\title{
Variable disease severity in Saudi Arabian and Sudanese families with c.3924 + 2 T > C mutation of LAMA2
}

\author{
Claudia Di Blasi ${ }^{1}$, Emanuela Bellafiore ${ }^{1}$, Mustafa AM Salih², M Chiara Manzini ${ }^{3}$, Steven A Moore ${ }^{4}$, \\ Mohammed Z Seidahmed ${ }^{5}$, Maowia M Mukhtar ${ }^{6}$, Zein A Karrar ${ }^{7}$, Christopher A Walsh³ ${ }^{3}$ Kevin P Campbell, \\ Renato Mantegazza ${ }^{1}$, Lucia Morandi ${ }^{1}$ and Marina Mora ${ }^{1 *}$
}

\begin{abstract}
Background: Congenital muscular dystrophy type $1 \mathrm{~A}$ is caused by mutations in the LAMA2 gene that encodes the laminin $\alpha 2$ chain, a component of the skeletal muscle extracellular matrix protein laminin-211. The clinical spectrum of the disease is more heterogeneous than previously thought, particularly in terms of motor achievement and disease progression. We investigated clinical findings and performed molecular genetic analysis in 3 families from Saudi Arabia and 1 from Sudan in whom congenital muscular dystrophy 1A was suspected based on homozygosity mapping and laminin $\alpha 2$ chain deficiency.

Methods: We investigated 9 affected individuals from 1 Sudanese and 3 Saudi families in whom MDC1A was suggested by clinical, neuroimaging and/or pathological findings and by homozygosity mapping at the LAMA2 locus. Morphological and immunohistochemical analysis were performed in 3 patients from the 3 Saudi families. SSCP analysis, DNA sequencing and microsatellite analysis were carried out in the 4 index cases.

Results: A previously described mutation in the LAMA2 gene, a homozygous $T>C$ substitution at position +2 of the consensus donor splice site of exon 26, was found in the 4 index patients. Clinical evaluation of 9 patients from the 4 families revealed variable disease severity particularly as regards motor achievement and disease progression. Microsatellite analysis showed an identical mutation-associated haplotype in the 4 index cases indicating a founder effect of the mutation in all 4 families.

Conclusions: Our data provide further evidence that the clinical spectrum of MDC1A due to a single mutation is heterogeneous, particularly in terms of motor achievement and disease progression, making it difficult to give a reliable prognosis even in patients with identical LAMA2-associated haplotype. The c.3924 + 2 T > C mutation to date has been found only in patients originating from the Middle East or Sudan; therefore laminin 2 chain deficiency in patients from those regions should initially prompt a search for this mutation.
\end{abstract}

Keywords: MDC1A, LAMA2, gene, Laminin a2 chain, Merosin

\section{Background}

Congenital muscular dystrophy type $1 \mathrm{~A}(\mathrm{MDC} 1 \mathrm{~A})$ is an autosomal recessive neuromuscular disorder caused by mutations in the LAMA2 gene encoding the laminin $\alpha 2$ chain [1] a component of the skeletal muscle extracellular matrix protein laminin-211 [2]. Laminin-211, the most

\footnotetext{
* Correspondence: mmora@istituto-besta.it

'Division of Neuromuscular Diseases and Neuroimmunology, Fondazione IRCCS Istituto Neurologico C. Besta, Milan, Italy

Full list of author information is available at the end of the article
}

abundant laminin in muscle, is also expressed in Schwann cells, synaptic basal lamina of peripheral nerves, heart, epidermis and fetal trophoblastic tissue [3]. MDC1A is characterized by generalized hypotonia and severe muscle weakness at birth with delayed motor development, proximal joint contractures, inability to achieve independent walking, high CK levels and a clinically asymptomatic abnormality of the central white matter on brain magnetic resonance imaging (MRI) [4-6]. Several studies have also documented respiratory insufficiency, often leading to

\section{Biomed Central}

(c) 2011 Mora et al; licensee BioMed Central Ltd. This is an Open Access article distributed under the terms of the Creative Commons Attribution License (http://creativecommons.org/licenses/by/2.0), which permits unrestricted use, distribution, and reproduction in any medium, provided the original work is properly cited. 
death in early childhood, and feeding difficulties. Clinical and subclinical cardiomyopathy, sensory and motor demyelinating neuropathy, and (late) external ophthalmoplegia, also occur [7]. Numerous mutations have now been identified in the LAMA2 gene, resulting in either complete or partial protein deficiency. However, the clinical spectrum is more heterogeneous than previously thought: a severe phenotype associated with partial expression of a laminin $\alpha 2$ chain isoform has been reported [8] as well as clinically mild forms with total lack of laminin $\alpha 2$ chain [9-11].

In the present study we report on three consanguineous Saudi Arabian families and a Sudanese family with the previously described [12] homozygous mutation c. $3924+2 \mathrm{~T}>\mathrm{C}$ in the LAMA2 gene. This mutation leads to aberrant splicing of exon 26 and results in an inframe deletion of 63 amino acid residues from domain IVa of the laminin $\alpha 2$ chain. We also performed haplotype analysis to investigate a hypothesized founder effect of this mutation, and examined the relationship between the mutation and clinical phenotype in the 4 families.

\section{Methods}

\section{Subjects}

Inclusion criteria for this study were a) clinical, neuroimaging and/or pathological findings suggestive of MDC1A; and b) homozygosity at the LAMA2 locus if consanguinity was confirmed or suspected. We investigated 9 affected individuals from 4 families. Patients 1 and 2, a male and a female, were Sudanese; they were born to parents from the same small village and had 7 healthy siblings. Patient 3 and 4 were males born to 3 rd cousin Saudi parents; family history revealed 2 deceased affected siblings with the same diagnosis and 5 healthy siblings. Patients 5 and 6 were both males born to a 1st cousin Saudi union and had 5 unaffected brothers. Patients 7, 8 and 9 were one male and two females also born to a 1st cousin Saudi union with another 2 unaffected male and female offspring. All patients were examined by a pediatric neurologist at a tertiary referral clinic and clinical features are summarized in Additional file 1: Table S1. A muscle biopsy was performed after informed consent in patients 3, 5, 6 and 8 .

Written, informed consent was obtained from the subjects or their parents/legal guardians. Research was conducted according to protocols approved by the Institutional Review Boards of Children's Hospital Boston, University of Iowa, King Saud University and Besta Neurological Institute, and in compliance with the Helsinki Declaration and local legislation.

\section{Immunohistochemistry}

Immunohistochemical analyses were performed on muscle biopsies from patients 3, 6 and 8, from the 3 Saudi families. Patient 3's muscle was analyzed using the following anti-human laminin $\alpha 2$-chain monoclonal antibodies: $5 \mathrm{H} 2$, recognizing the G-domain (Gibco/BRL, Gaithersburg, USA), 300 kDa NCL-merosin (Novocastra, New Castle-upon-Tyne, UK), and 4H8-2 (gift to KPC from L. Sorokin) recognizing the N-terminus of the protein. Patient 8 's muscle was tested only with the 300 $\mathrm{kDa}$ monoclonal.

In addition, the expression of dystrophin [6A9 at 1:50, Developmental Studies Hybridoma Bank (DSHB), The University of Iowa], $\alpha$-dystroglycan (VIA4-1 at 1:50, Millipore), $\alpha$-dystroglycan (7D11 at 1:100, DSHB), perlecan (a716 at 1:1000, Millipore) and collagen VI (5 C6 at $1: 20$, DSHB) were investigated in patient 3 . Dystrophin, $\alpha$-, $\beta$ - and $\gamma$-sarcoglycan (all from Novocastra) were tested in patients 6 and 8 .

Cryosections were incubated in primary antibodies diluted in PBS for 1-2 $\mathrm{h}$ at room temperature or overnight at $4^{\circ} \mathrm{C}$. Slides were washed $5 \mathrm{~min} \times 2$ in PBS, then secondary antibodies were applied in PBS for $30 \mathrm{~min}-1$ $\mathrm{h}$ at room temperature. After washing again $5 \mathrm{~min} \times 2$ in PBS, coverslips were mounted using ProLongGold with DAPI (Molecular Probes Inc, Eugene, OR, USA). Secondary antibodies were either goat-anti-mouse tagged with AlexaFluor488 or goat-anti-rat tagged with AlexaFluor594 (both from Molecular Probes).

\section{Molecular analyses}

Genomic DNA was extracted from peripheral blood and analyzed by the polymerase chain reaction touchdown method using oligonucleotide primers flanking the intron-exon junctions of all 65 LAMA2 exons (exon numbering according to the Leiden muscular dystrophy database) [10]. Aberrant conformers, identified by single-strand conformation polymorphism (SSCP) analysis, were sequenced using an ABI Prism 3100 analyzer (Applied Biosystems, Foster City, CA, USA).

Total RNA was prepared from skeletal muscle using TRI Reagent (Ambion, Inc. Austin, TX). The isolated RNA was reverse transcribed using a First-Strand cDNA Synthesis Kit (Roche Molecular Biochemicals, Basel, Switzerland), the resulting cDNA was amplified by reverse transcriptase PCR (RT-PCR) and sequenced using appropriate primers.

\section{Haplotyping}

Haplotype analysis was performed on genomic DNA using microsatellite markers provided by Genethon human genetic linkage map [13] and flanking the LAMA2 gene: upstream (D6S407) and downstream (D6S1620, and D6S1705); and six intragenic polymorphisms: G1905A, A2848G, G5515A, A5551G, C5579A and G6286A [14]. Allele frequency of polymorphisms in a reference population are reported in Guicheney et al. [14]. 


\section{Results}

Clinical findings are summarized in Additional file 1: Table S1. All patients were floppy babies and manifested with generalized hypotonia. Severe proximal weakness was also present from birth or developed within the first 6 months. In all cases motor milestones were delayed. Five of the 9 patients achieved independent walking at 3, 3.5 and 4 years, which was retained at least until 8, 11,12 or 13 years respectively, when last seen. Patients 3-6, who never walked, could sit or stand with or without support. CK was normal in patient 9, and slightly to markedly increased in all others.

Electrocardiogram (performed in 5 patients) and echocardiogram (performed in 4 patients) were normal; cardiac signs were reported in none of the patients. Respiratory support was necessary in patient 3 who died of respiratory failure at 7 years and in patient 5 who also died of respiratory failure at 16 years. No mental retardation, epilepsy or eye abnormalities were observed. MRI or CT, performed in 8 patients, revealed white matter changes in all cases (Figure 1). Patients 3 and 6 underwent EMG, and myopathic features were found in both cases.

A muscle biopsy from patient 3 (taken at 5 weeks) showed mild dystrophic features; whereas muscle biopsies from patients 5 (taken at 3 years and 2 months), 6
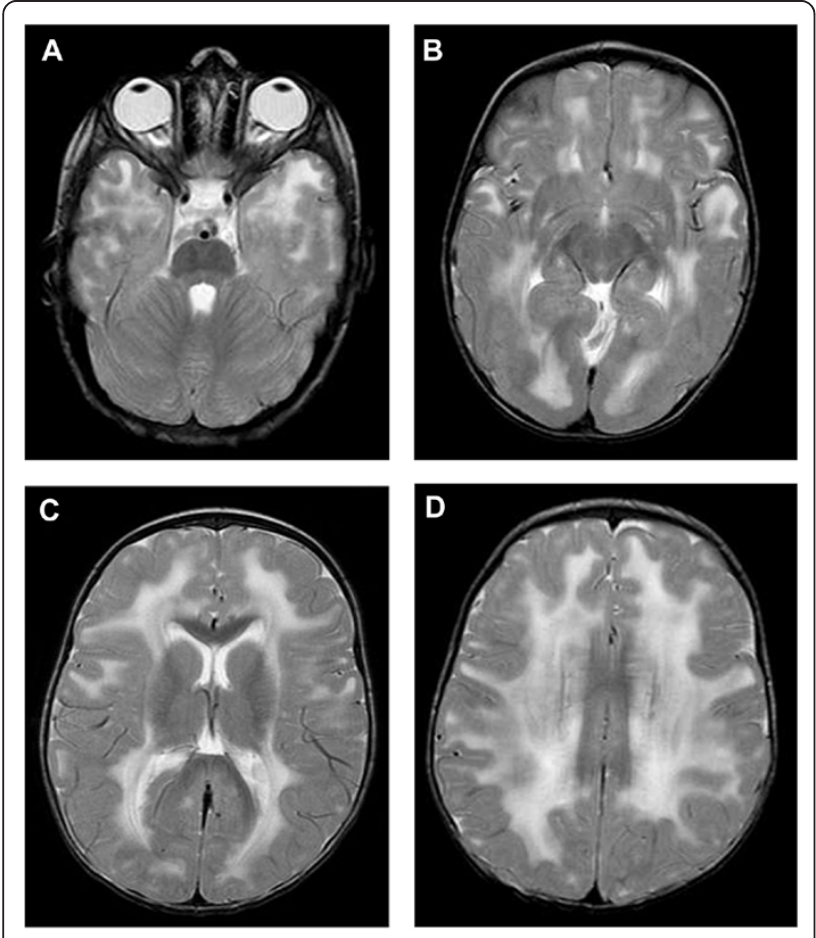

Figure 1 T2-weighted MRI images of patient 7, taken at the age of 19 months. Showing abnormal periventricular and subcortical white matter signal. (taken at 5 years) and 8 (taken at 4 years) showed marked dystrophic features. Immunofluorescence analysis of the laminin $\alpha 2$ chain was only performed in patient 3 (with 3 antibodies) and in patient 8 (1 antibody); this revealed greatly reduced staining intensity with the 3 antibodies in patient 3 (Figure 2) and with the single antibody in patient 8 (data not shown). Dystrophin and dystrophin-associated proteins were normal in patients 3,6 and 8 .

SSCP analysis in patients 1, 4, 5 and 7 (index cases) revealed abnormal conformers in exon 26. The exon was sequenced and showed a $\mathrm{T}>\mathrm{C}$ substitution at position +2 of the consensus donor splice site. This mutation has been described previously in two siblings from a consanguineous Saudi family unrelated to ours [12]. Direct sequencing of the cDNA revealed a $189 \mathrm{bp}$ inframe deletion, corresponding to aberrant skipping of the whole of exon 26, with loss of 63 amino acids (residues 1246-1308) from domain IVa of the protein (See Additional file 2: Figure S1).

Because of the consanguinity in the Saudi families and presumed consanguinity in the Sudanese family, it is likely that all affected siblings are homozygous for this mutation.

Investigation of flanking and intragenic microsatellite markers of the LAMA2 gene in the 4 index cases indicated an identical mutation-associated haplotype (containing the mutation) between marker D6S407 and

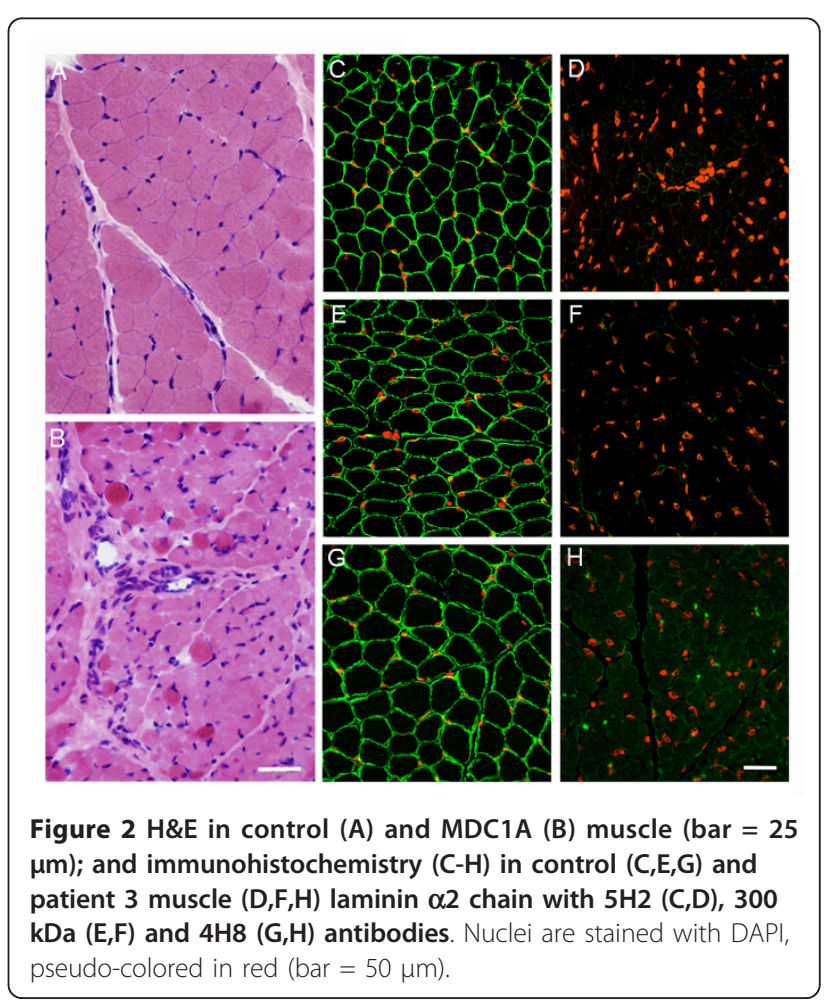


intragenic polymorphism G6286A (data not shown), suggesting remote consanguinity and a founder effect in all 4 families. By contrast, the downstream markers (D6S1620, and D6S1705) were not identical in the 4 cases.

\section{Discussion}

In 3 families from Saudi Arabia and 1 from Sudan we have identified a previously reported homozygous c.3924 $+2 \mathrm{~T}>\mathrm{C}$ mutation in the LAMA2 gene associated with variable clinical phenotype. The main phenotypic differences among our 9 cases regard motor achievement. Patients 1 and 2 from the Sudanese family walked at 4 years; patients 7, 8 and 9 from a Saudi family walked at $3,3.5$ and 4 years, respectively. These 5 patients were still walking at $8,11,12$ and 13 years when last seen, while patients 3, 4, 5, and 6 from the 2 other Saudi Arabian families never walked.

CK levels were also variable, being very high (5.5 $16.8 \times$ normal) in patients $3,6,7$, and 8 ; high (1.2 - 4.4 $\times$ normal) in patients $1,2,4$ and 5 ; and normal in patient 9.

Features common to all were floppiness in infancy, delayed motor milestones or failure to achieve walking, brain white matter attenuation on MRI or CT (not done in 1 patient) and development of joint contractures/foot deformities. Eye and cardiac abnormalities were not observed. In patients 3 and 5 respiratory compromise was present, and both died of respiratory failure at 7 and 16 years, respectively.

In 1997 Allamand et al. [12] reported on a brother and sister from a consanguineous Saudi family with the same LAMA2 mutation as found in our patients (but characterized as $3973+2 \mathrm{~T}>\mathrm{C}$ according to the previous $L A M A 2$ nucleotide sequence numbering). Both were mildly affected: the boy at 3.5 years had muscle hypotonia and inadequate head control, but walked at 26 months; his younger sister also had hypotonia from early infancy and poor head control and achieved walking at 3 years 8 months. Both had slightly reduced laminin $\alpha 2$ chain expression as investigated by 2 antibodies recognizing the $\mathrm{G}$ domain, and highly reduced expression using an antibody recognizing the $\mathrm{N}$ terminal. These results demonstrated for the first time that use of more than one antibody can provide valuable indications as to what domain(s) of the laminin $\alpha 2$ chain may be affected in CMD patients. Thereafter, this procedure became the standard method for staining muscle of patients with CMD and has also been used for prenatal diagnosis.

By contrast, in our patient 3, analyzed with 3 different antibodies, laminin $\alpha 2$ chain expression was markedly reduced: clearly more so than the cases described in Allamand et al. [12]. He was the most severely affected of our cases.
It is noteworthy that our cases show a much wider clinical spectrum than suggested by the siblings described by Allamand et al. [12]: from the very severe patient 3 and his brother (patient 4 who never walked or sat unaided), to patients $1,2,8$ and 9 who were still walking at latest examination.

We previously reported two siblings from a consanguineous family with partial laminin $\alpha 2$ chain deficiency due to an in-frame deletion and exceptionally mild clinical manifestations [15]. The proband was a 39 year-old man whose symptoms (difficulty in running and jumping), first appeared at age 15 years and worsened very slowly. When examined, the proband's sister was found to have a similar though even milder clinical picture. Siala et al. [16] reported that clinical severity differed between two siblings with the same out-of-frame mutation in the LAMA2 gene, which was unrelated to laminin $\alpha 2$ chain expression (completely undetectable in both cases). Such clinical variability implies the presence of other genetic or epigenetic factors able to influence disease phenotype (see Heydemann et al. [17]).

The data of the present study provide further evidence that the clinical spectrum of MDC1A is more heterogeneous than previously thought; motor achievement and disease progression are particularly variable, making it difficult to formulate prognoses even in patients with an identical LAMA2- associated haplotype. Modifier genes, such as those coding for proteins that interact with laminin $\alpha 2$, and/or epigenetic factors, for instance those involved in regulatory signaling functions, are likely to contribute to the observed phenotypic variability. A drawback of the present study is that muscle biopsies were stained for laminin $\alpha 2$ in only 2 cases and extensive immunohistological characterization was only possible in one case.

We emphasize, finally, that the identical intragenic polymorphisms and upstream microsatellite markers of the LAMA2 gene in our patients, strongly suggest a founder effect. The mutation probably originated in Saudi Arabia since studies on severe childhood autosomal recessive muscular dystrophy (SCARMD), the common form of muscular dystrophy in North Africa and the Arabian Peninsula [18-21] indicate that affected families from the same tribe migrated from central Saudi Arabia to the Sudan - crossing the Red Sea - in the 12th and 13th centuries [22]. Furthermore, in Saudi Arabia the mutation may not be rare since we have recently learned (personal communication of Dr. Thomas L. Winder to SAM) of 3 Saudi patients with this mutation, 2 of whom are homozygous and one who is heterozygous. A few more cases, all originating from the Middle East, are reported in the Leiden database http:// www.dmd.nl/. The clinical implication is that a laminin $\alpha 2$ chain deficiency in Middle Eastern or Sudanese 
patients should initially prompt a search for the c.3924 $+2 \mathrm{~T}>\mathrm{C}$ mutation in the LAMA2 gene.

\section{Conclusions}

Our data provide further evidence that the clinical spectrum of MDC1A due to a single mutation is heterogeneous, particularly in terms of motor achievement and disease progression, making it difficult to give a reliable prognosis even in patients with identical LAMA2-associated haplotype.

The c. $3924+2 \mathrm{~T}>\mathrm{C}$ mutation to date has been found only in patients originating from the Middle East or Sudan; therefore laminin 2 chain deficiency in patients from those regions should initially prompt a search for this mutation.

\section{Additional material}

Additional file 1: Table S1. Clinical findings.

Additional file 2: Figure S1. Sequencing of genomic DNA from control (A) and patient (B) showing the T>C transition at position +2 of the consensus donor splice site of exon 26. Direct sequencing of the cDNA revealing a $189 \mathrm{bp}$ in-frame deletion, corresponding to aberrant skipping of the whole of exon 26: (C) control and (D) patient.

\section{Acknowledgements}

This study was partially supported by the Italian Ministry of Health (MM, LM and RM), the NINDS (RO1 NS 35129 to CAW), the Muscular Dystrophy Association (Development Grant to MCM). The University of lowa Wellstone Muscular Dystrophy Cooperative Research Center is funded by NIH U54 NS053672 (SAM and KPC). CAW and KPC are investigators of the Howard Hughes Medical Institute.

The authors thank Don Ward for help with the English, Daniel Rakiec and Jillian Felie at Children's Hospital, Boston for help with microsatellite analysis and sequencing, Terese Nelson at the University of lowa for immunostaining patient 3, and Joel Carl at the University of lowa for assembling the photomicrographs in Figure 2.

\section{Author details}

'Division of Neuromuscular Diseases and Neuroimmunology, Fondazione IRCCS Istituto Neurologico C. Besta, Milan, Italy. ${ }^{2}$ Division of Pediatric Neurology, Department of Pediatrics, College of Medicine, King Saud University, Riyadh, Saudi Arabia. ${ }^{3}$ Howard Hughes Medical Institute, Division of Genetics and Manton Center for Orphan Disease Research, Children's Hospital, Boston, MA 02115, USA. ${ }^{4}$ Department of Pathology, Roy J. and Lucille A. Carver College of Medicine, University of lowa, lowa City, IA 52242, USA. ${ }^{5}$ Department of Pediatrics, Security Forces Hospital, Riyadh, Saudi Arabia. ${ }^{6}$ Institute of Endemic Diseases, University of Khartoum, Khartoum, Sudan. ${ }^{7}$ Department of Pediatrics and Child Health, College of Medicine, University of Khartoum, Khartoum, Sudan. ${ }^{8}$ Howard Hughes Medical Institute and Department of Molecular Physiology and Biophysics, Roy J. and Lucille A. Carver College of Medicine, University of lowa, lowa City, IA 52242, USA.

\section{Authors' contributions}

CDB carried out the molecular and microsatellite analysis and drafted the manuscript; EB performed molecular analysis; MAMS evaluated clinical and neurologic features of the patients, collected DNA and muscle biopsies and revised the manuscript critically for important intellectual content; MCM carried out homozygosity mapping and linkage analysis; SAM performed immunochemical evaluation of muscle biopsies and prepared the figures; MZS, MMM and ZAK evaluated neurologic, neurophysiologic and MRI features; CAW and KPC supervised the study and critically revised the manuscript; LM and RM contributed to writing the clinical reports, revised the manuscript critically and provided financial support; MM was responsible for study design, supervised the study and manuscript completion. All authors read and approved the final manuscript.

\section{Competing interests}

The authors declare that they have no competing interests.

Received: 20 October 2011 Accepted: 13 December 2011 Published: 13 December 2011

\section{References}

1. Helbling-Leclerc A, Zhang X, Topaloglu H, Cruaud C, Tesson F, Weissenbach J, Tomé FM, Schwartz K, Fardeau M, Tryggvason K, et al: Mutations in the laminin alpha 2-chain gene (LAMA2) cause merosindeficient congenital muscular dystrophy. Nat Genet 1995, 11(2):216-218.

2. Aumailley M, Bruckner-Tuderman L, Carter WG, Deutzmann R, Edgar D, Ekblom P, Engel J, Engvall E, Hohenester E, Jones JC, et al: A simplified laminin nomenclature. Matrix Biol 2005, 24(5):326-332.

3. Leivo I, Engvall E: Merosin, a protein specific for basement membranes of Schwann cells, striated muscle, and trophoblast, is expressed late in nerve and muscle development. Proc Natl Acad Sci USA 1988, 85(5):1544-1548

4. Tomé FM, Evangelista T, Leclerc A, Sunada Y, Manole E, Estournet B, Barois A, Campbell KP, Fardeau M: Congenital muscular dystrophy with merosin deficiency. C R Acad Sci III 1994, 317(4):351-357.

5. Dubowitz V, Fardeau M: Proceedings of the 27th ENMC sponsored workshop on congenital muscular dystrophy. 22-24 April 1994, The Netherlands. Neuromuscul Disord 1995, 5(3):253-258.

6. Philpot J, Sewry C, Pennock J, Dubowitz V: Clinical phenotype in congenital muscular dystrophy: correlation with expression of merosin in skeletal muscle. Neuromuscul Disord 1995, 5(4):301-305.

7. Geranmayeh F, Clement E, Feng LH, Sewry C, Pagan J, Mein R, Abbs S, Brueton L, Childs AM, Jungbluth H, et al: Genotype-phenotype correlation in a large population of muscular dystrophy patients with LAMA2 mutations. Neuromuscul Disord 2010, 20(4):241-50.

8. Pegoraro E, Fanin M, Trevisan CP, Angelini C, Hoffman EP: A novel laminin alpha2 isoform in severe laminin alpha2 deficient congenital muscular dystrophy. Neurology 2000, 55(8):1128-1134.

9. Prandini P, Berardinelli A, Fanin M, Morello F, Zardini E, Pichiecchio A, Uggetti C, Lanzi G, Angelini C, Pegoraro E: LAMA2 loss-of-function mutation in a girl with a mild congenital muscular dystrophy. Neurology 2004, 63(6):1118-1121.

10. Di Blasi C, Piga D, Brioschi P, Moroni I, Pini A, Ruggieri A, Zanotti S, Uziel G, Jarre L, Della Giustina E, et al: LAMA2 gene analysis in congenital muscular dystrophy: new mutations, prenatal diagnosis, and founder effect. Arch Neurol 2005, 62(10):1582-1586.

11. Vigliano P, Dassi P, Di Blasi C, Mora M, Jarre L: LAMA2 stop-codon mutation: Merosin-deficient congenital muscular dystrophy with occipital polymicrogyria, epilepsy and psychomotor regression. Eur J Paediatr Neurol 2009, 13(1):72-76.

12. Allamand V, Sunada Y, Salih MA, Straub V, Ozo CO, Al-Turaiki MH, Akbar M, Kolo T, Colognato H, Zhang $X$, et al: Mild congenital muscular dystrophy in two patients with an internally deleted laminin alpha2-chain. Hum Mol Genet 1997, 6(5):747-752.

13. Dib C, Fauré S, Fizames C, Samson D, Drouot N, Vignal A, Millasseau P, Marc S, Hazan J, Seboun E, et al: A comprehensive genetic map of the human genome based on 5264 microsatellites. Nature 1996, 380(6570):152-154.

14. Guicheney P, Vignier N, Zhang X, He Y, Cruaud C, Frey V, Helbling-Leclerc A, Richard P, Estournet B, Merlini L, et al: PCR based mutation screening of the laminin alpha2 chain gene (LAMA2): application to prenatal diagnosis and search for founder effects in congenital muscular dystrophy. J Med Genet 1998, 35(3):211-217.

15. Di Blasi C, He Y, Morandi L, Cornelio F, Guicheney P, Mora M: Mild muscular dystrophy due to a nonsense mutation in the LAMA2 gene resulting in exon skipping. Brain 2001, 124(Pt 4):698-704.

16. Siala O, Kammoun Feki F, Louhichi N, Hadj Salem I, Gribaa M, Elghzel H, Saad A, Triki C, Fakhfakh F: Molecular prenatal diagnosis of muscular dystrophies in Tunisia and postnatal follow-up role. Genet Test 2008, 12(4):581-586. 
17. Heydemann A, Doherty KR, McNally EM: Genetic modifiers of muscular dystrophy: implications for therapy. Biochim Biophys Acta 2007, 1772(2):216-228.

18. Salih MA, Omer MI, Bayoumi RA, Karrar O, Johnson M: Severe autosomal recessive muscular dystrophy in an extended Sudanese kindred. Dev Med Child Neurol 1983, 25(1):43-52.

19. Salih MA: Childhood muscular dystrophy: an African review. Ann Trop Paediatr 1985, 5(4):167-173.

20. Salih MA, Mahdi AH, al-Jarallah AA, al Jarallah AS, al-Saadi M, Hafeez MA, Aziz SA: Childhood neuromuscular disorders: a decade's experience in Saudi Arabia. Ann Trop Paediatr 1996, 16(4):271-280.

21. Salih MA, Mahdi AH, al-Rikabi AC, al-Bunyan M, Roberds SL, Anderson RD, Campbell KP: Clinical and molecular pathological features of severe childhood autosomal recessive muscular dystrophy in Saudi Arabia. Dev Med Child Neurol 1996, 38(3):262-270.

22. Salih MAM: Muscular dystrophies and myopathies in Arab populations. In Genetic Disorders among Arab Populations. 2 edition. Edited by: Teebi AS. Berlin Heidelberg: Springer-Verlag; 2010:145-179.

doi:10.1186/1756-0500-4-534

Cite this article as: Di Blasi et al: Variable disease severity in Saudi Arabian and Sudanese families with c.3924 + 2 T > C mutation of LAMA2. BMC Research Notes 2011 4:534.

\section{Submit your next manuscript to BioMed Central} and take full advantage of:

- Convenient online submission

- Thorough peer review

- No space constraints or color figure charges

- Immediate publication on acceptance

- Inclusion in PubMed, CAS, Scopus and Google Scholar

- Research which is freely available for redistribution

Submit your manuscript at www.biomedcentral.com/submit 